Review

\title{
Interventions for coordination of walking following stroke: Systematic review
}

\author{
Kristen L. Hollands ${ }^{a, *}$, Trudy A. Pelton ${ }^{b}$, Sarah F. Tyson ${ }^{a}$, Mark A. Hollands ${ }^{c}$, Paulette M. van Vliet ${ }^{d}$ \\ ${ }^{a}$ School of Health, Sport and Rehabilitation Sciences, University of Salford, Frederick Rd. Campus, Salford M6 6PU, UK \\ b .School of Psychology, College of Life and Environmental Sciences, University of Birmingham, UK \\ '.School of Sport and Exercise Sciences, College of Life and Environmental Sciences, University of Birmingham, UK \\ d.School of Health Sciences, University of Newcastle, Australia
}

A R T I C LE I N F O

\section{Article history:}

Received 5 May 2011

Received in revised form 20 July 2011

Accepted 22 October 2011

\section{Keywords:}

Stroke

Gait

Coordination

Rehabilitation

\begin{abstract}
A B S T R A C T
Impairments in gait coordination may be a factor in falls and mobility limitations after stroke. Therefore, rehabilitation targeting gait coordination may be an effective way to improve walking post-stroke. This review sought to examine current treatments that target impairments of gait coordination, the theoretical basis on which they are derived and the effects of such interventions.

Few high quality RCTs with a low risk of bias specifically targeting and measuring restoration of coordinated gait were found. Consequently, we took a pragmatic approach to describing and quantifying the available evidence and included non-randomised study designs and limited the influence of heterogeneity in experimental design and control comparators by restricting meta-analyses to pre- and post-test comparisons of experimental interventions only.

Results show that physiotherapy interventions significantly improved gait function and coordination. Interventions involving repetitive task-specific practice and/or auditory cueing appeared to be the most promising approaches to restore gait coordination. The fact that overall improvements in gait coordination coincided with increased walking speed lends support to the hypothesis that targeting gait coordination gait may be a way of improving overall walking ability post-stroke. However, establishing the mechanism for improved locomotor control requires a better understanding of the nature of both neuroplasticity and coordination deficits in functional tasks after stroke. Future research requires the measurement of impairment, activity and cortical activation in an effort to establish the mechanism by which functional gains are achieved.
\end{abstract}

(c) 2011 Elsevier B.V. All rights reserved.

\section{Background}

To restore efficient, independent functional walking, the relationship of movements between body segments needs to be adaptable to allow variations to the walking pattern according to environmental demands; such as changes in walking speed or direction and obstacle avoidance. This means that rehabilitation must restore a coordinated gait pattern which may be defined as "An ability to maintain a context-dependent and phase-dependent cyclical relationship between different body segments or joints in both spatial and temporal domains." [1] However, stroke survivors demonstrate many deficits of gait coordination which persist despite rehabilitation, including altered temporal and spatial coordination between the head, trunk and pelvis [2,3] and impaired pelvic, knee, and ankle control during stance and impaired excursions and timing during swing phase [4]. Poor interlimb coordination is reflected by asymmetries in propulsive

\footnotetext{
* Corresponding author. Tel.: +440161295 3238.

E-mail address: k.hollands@salford.ac.uk (K.L. Hollands).
}

forces between the paretic and non-paretic limbs [5], step lengths, widths and stance and swing phase durations [6-8]. All of these impairments in gait coordination underlie overall decreased walking speed and endurance [9].

If gait coordination is impaired, then the ability to alter the basic gait pattern in response to environmental demands may also be impaired [10]. Indeed, restoration of gait adaptability has been associated with lower falls risk [11] and reduced motor coordination is correlated with poorer motor recovery [12]. Thus, poor coordination of body segments (such as the trunk, pelvis or lower limbs) may be a mechanism underlying the frequent falls reported by stroke survivors $[13,14]$ and, rehabilitation targeting impairments in gait coordination may be a way to improve walking ability post-stroke.

Several systematic reviews [15-17] examining the effectiveness of individual treatment approaches on gait speed have concluded there is insufficient evidence on which to determine the effectiveness of these approaches. This review, therefore, seeks to identify all interventions which aim to address gait coordination (as a putative mechanism of gait dysfunction) in stroke survivors and explore their effects on gait coordination and overall gait ability. This will facilitate 
an examination of the hypothesis that restoration of a coordinated gait pattern is a mechanism to improve overall walking ability, as well as to identify the gaps in knowledge and interventions which show promise for further study.

\section{Methods of the review}

The aims of this review were to:

(1) Identify current non-surgical and non-pharmacological rehabilitation interventions used to treat gait coordination impairments after stroke.

(2) Determine the effects of identified interventions on measures of gait coordination and overall walking ability compared with no treatment.

In order to identify gaps in knowledge base and directions for future research, the theoretical basis for interventions is discussed. Evidence for the hypothesis that improved gait coordination may facilitate improved overall walking ability is also examined.

\subsection{Databases searched}

The following databases were searched:

- Cochrane Stroke Group Trials Register.

- Cochrane Central Register of Controlled Trials (CENTRAL) (The Cochrane Library).

- MEDLINE (1950 to present).

- EMBASE (1980 to present).

- CINAHL (1982 to present).

- AMED (1985 to present).

- National Institutes of Health (NIH) Clinical Trials Database host: NIH (http://clinicaltrials.gov/ct).

- National Institute of Clinical Studies (http://www.med.monash.edu.au/healthservices/cce/index.html).

The following rehabilitation specific databases which include both peer reviewed and some un-peer reviewed content were searched:

- Otseeker (http://www.otseeker.com/).

- OT Search (http://www.aota.org/otsearch/index.asp).

- Physiotherapy Evidence database (PEDro, http://www.pedro.fhs.usyd.edu.au/index.html).

- Chartered Society of Physiotherapy Research Database.

- REHABDATA(http://www.naric.com/research/rehab/default.cfm).

\subsection{Key words and limits}

The search strategy used a combination of controlled vocabulary (MeSH) and free text terms, was limited to English papers with human participants and was used for MEDLINE and modified to suit other databases.

\subsection{Selection criteria}

\subsubsection{Participants}

We included participants with a clinical diagnosis of stroke [18], regardless of lesion site, time since onset, co-morbidities, previous strokes or initial motor impairment.

\subsubsection{Intervention}

Any physiotherapy intervention or experimental manipulation to effect gait coordination, whether a single intervention session or more complex treatment; provided the design yielded evidence for the potential efficacy of the intervention. For example, repeated trials of walking overground were considered locomotor practice and studies involving such a manipulation/intervention were included.

\subsubsection{Comparisons}

Studies that compared measurement of an intervention with a control, be that of a group or condition, were included. This included randomised and quasi-randomised controlled trials, case-control studies, cohort studies, and before-after studies. Studies which only reported data for comparisons between healthy control groups and stroke participants or had no control or baseline comparisons were excluded.

\subsubsection{Outcome measure}

Studies were required to include at least one measure of gait coordination, defined as the following kinematics: spatial and temporal indices of gait symmetry, cross correlations of lower limb or axial segment displacement, velocity or acceleration trajectories or measures of relative phase (see [1] for further details). Studies were excluded if outcomes were presented as means averaged across limbs and hence no indication of interlimb coordination could be extracted. Gait speed was extracted to reflect overall function, but studies which reported gait speed as the only indicator of coordination were excluded as the information gait speed provides regarding underlying impairments is limited [4,19-21]. Studies that did not explicitly state the objective was to determine the effects on gait coordination, but used a coordination measure as an outcome measure were included.

\subsection{Identification of relevant trials}

Selection of studies was performed according to Cochrane Review guidelines [22]. Two of the authors (KH, PvV) read each reference and, based on the inclusion criteria, independently ranked these as 'possibly relevant', or 'definitely irrelevant'. If both identified a trial as 'definitely irrelevant' we excluded it. Consensus was achieved through discussion, including a third author if necessary (TP).

\subsection{Data analysis}

$\mathrm{KH}$ and PvV independently assessed the methodological quality of selected studies using a modified version of the Joanna Briggs Institute (JBI) critical appraisal checklist for cohort/case control [23]. For rigour and detail, additional questions from Downs and Black's checklist [24] were added. The authors then independently extracted means and standard deviations from each outcome measure as well as participant demographics (Table 1.1) and details of the study design (Tables 2.1 and 2.2).

Different mathematical expressions of gait symmetry are highly inter-correlated [25] indicating that they measure the same construct of gait coordination and can therefore be validly combined in meta-analyses. We therefore calculated the effect size for measures of gait symmetry using standardized differences in means (SMD). Standard deviations for baseline and postintervention (or with and without conditions, according to study comparisons) were extracted from each study for pooling in Review Manager 5 software (RevMan. Copenhagen: the Nordic Cochrane Centre, The Cochrane Collaboration, 2008). Metaanalysis was also performed on self-selected gait speed as an indicator of the effect of treatment approaches on overall gait function. Some studies reported data which were not suitable for pooling and some intervention types had only one included trial, insufficient to be pooled. Data from these studies were not 
Table 1.1

Demographics of participants in included studies (mean $\{\mathrm{SD}\}$ ).

\begin{tabular}{|c|c|c|c|c|c|c|}
\hline Study & Number of participants & Male:female & Mean Age (years) & R:L paretic & Time since stroke (months) & Walking Speed $(\mathrm{m} / \mathrm{s})$ \\
\hline \multicolumn{7}{|l|}{ Task specific practice } \\
\hline Chen, 2005 & 6 & 03:03 & $60\{7\}$ & 03:03 & $44\{41\}$ & $0.52\{0.22\}$ \\
\hline Ford, 2007 & 11 & $10: 01$ & {$[14-78]$} & 05:06 & $>1$ year & $0.877\{0.36\}$ \\
\hline Harris-Love, 2001 & 18 & $12: 06$ & Unspecified & $07: 11$ & $39.5\{32\}$ & $0.5\{0.2\}$ \\
\hline Hornby, 2008 & 34 & $30: 18$ & $57\{11\}$ & $32: 16$ & $50\{51\}$ & $0.45\{0.19\}$ \\
\hline Lindquist 2007 & 8 & 06:02 & $56.6\{10.26\}$ & $02: 06$ & $17.3\{10.9\}$ & $0.43\{0.19\}$ \\
\hline Plummer, 2007 & 6 & 03:04 & $54.7\{15.4\}$ & 03:04 & $5.14\{1.21\}$ & $0.39\{0.22\}$ \\
\hline Reisman, 2007 & 13 & 09:04 & $51.77\{12.00\}$ & 07:06 & $52.07\{56.34\}$ & $1.13\{0.31\}$ \\
\hline Waajford, 1990 & 1 & 00:01 & 40 & 00:01 & 36 & $0.76\{0.02\}$ \\
\hline Westlake, 2009 & 16 & $13: 03$ & $58.6\{16.9\}$ & 07:09 & $43.8\{26.8\}$ & $0.62\{0.31\}$ \\
\hline Yang, 2007 & 25 & $14: 11$ & $59.46\{11.83\}$ & $16: 09$ & $48.96\{37.56\}$ & $0.85\{0.19\}$ \\
\hline Yang, 2005 & 13 & $19: 06$ & $63.38\{7.7\}$ & $16: 09$ & $5.45\{3.03\}$ & $0.414\{0.112\}$ \\
\hline McCain, 2008 & 7 & & $57.0\{17.6\}$ & 04:10 & $7.2\{1.39\}$ & \\
\hline Laufer, 2001 & 13 & $14: 11$ & $66.6\{7.2\}$ & $15: 10$ & $1.08\{0.707\}$ & $0.20\{0.12\}$ \\
\hline \multicolumn{7}{|c|}{ Ankle-foot orthotic interventions } \\
\hline Hausdorff, 2008 & 24 & $20: 04$ & $54.0\{13.5\}$ & $10: 14$ & $69.6\{62.4\}$ & $0.46\{0.25\}$ \\
\hline Krishnamoorthy, 2008 & 1 & 01:00 & 58 & 01:00 & 41 & $0.98\{0.49\}$ \\
\hline Lehmann, 1987 & 7 & 03:04 & {$[59-75]$} & 04:03 & {$[36-156]$} & 0.46 \\
\hline Jones, 1999 & 2 & 02:00 & {$[65,71]$} & 02:00 & {$[5,11]$} & {$[0.79,0.85]$} \\
\hline Wang, 2007 & 58 & $20: 14$ & $60.36\{13.95\}$ & $10: 24$ & $3.29\{1.17\}$ & \\
\hline Tyson, 2001 & 25 & $16: 09$ & $49.9\{1\}$ & $16: 09$ & $8.3\{5.5\}$ & $0.18\{0.1\}$ \\
\hline Tyson, 1998 & 4 & 03:01 & 62,24 & 02:02 & $36,9,12$ & \\
\hline \multicolumn{7}{|l|}{ Auditory cueing } \\
\hline Schauer, 2003 & 23 & & $59\{12\}$ & $11: 12$ & 1.76 & $0.64\{0.30\}$ \\
\hline Thaut, 1997 & 20 & & $73\{7\}$ & $10: 10$ & $0.536\{0.133\}$ & $0.328\{0.183\}$ \\
\hline Thaut, 2007 & 52 & 41: 37 & $69.2\{11.5\}$ & $12: 42$ & $0.71\{0.36\}$ & $0.235\{0.216\}$ \\
\hline Roerdink, 2007 & 9 & 08:02 & $63\{11.9\}$ & $10: 03$ & $37.7\{32.67\}$ & $0.859\{0.182\}$ \\
\hline Prassas, 1997 & 8 & 07:01 & $69.63\{11.06\}$ & 03:05 & $7.75\{7.24\}$ & \\
\hline \multicolumn{7}{|l|}{ Exercise } \\
\hline Silver, 2000 & 5 & 05:00 & $60.4\{2.7\}$ & 01:04 & $26\{4.6\}$ & $0.9\{0.2\}$ \\
\hline Sibley, 2008 & 36 & $22: 14$ & $65.4\{12.2\}$ & $12: 23,1$ bilateral & $1.66\{0.44\}$ & $0.853\{0.310\}$ \\
\hline Coombs, 2007 & 1 & 00:01 & 51 & 01:00 & 6 & \\
\hline Patterson, 2008 & 39 & $27: 15$ & $64.8\{8\}$ & $26: 16$ & $20.55\{64\}$ & $0.548\{0.263\}$ \\
\hline \multicolumn{7}{|c|}{ Miscellaneous interventions } \\
\hline Dunsky, 2008 & 17 & 02:15 & $57.47\{9.25\}$ & 06:11 & $46.29\{26.83\}$ & $0.38\{0.17\}$ \\
\hline Dickstein, 2004 & 1 & 01:00 & 69 & 00:01 & 3.33 & \\
\hline Yavuzer, 2006 & 25 & $10: 12$ & $59.8\{11.6\}$ & $09: 13$ & $11.1\{24.6\}$ & $0.36\{0.2\}$ \\
\hline
\end{tabular}

Note: Data is presented for the experimental group only for those studies employing a parallel group design.

Table 2.1

Summary of the methodological quality of non-randomised studies.

\begin{tabular}{|c|c|c|c|c|c|c|c|c|c|c|}
\hline \multirow[b]{2}{*}{ Intervention type } & \multirow[b]{2}{*}{ Aims } & \multirow[b]{2}{*}{$\begin{array}{l}\text { Theoretical } \\
\text { basis }\end{array}$} & \multirow[b]{2}{*}{$\begin{array}{l}\text { Baseline } \\
\text { characteristics } \\
\text { described }\end{array}$} & \multicolumn{3}{|c|}{ Experimental design } & \multicolumn{4}{|c|}{ Outcome measures } \\
\hline & & & & $\begin{array}{l}\text { Randomised } \\
\text { order of } \\
\text { trials }\end{array}$ & $\begin{array}{l}\text { Control } \\
\text { condition }\end{array}$ & $\begin{array}{l}\text { Blinding of } \\
\text { assessor }\end{array}$ & $\begin{array}{l}\text { Reliable } \\
\text { method }\end{array}$ & Valid & $\begin{array}{l}\text { Appropriate } \\
\text { statistics }\end{array}$ & $\begin{array}{l}\text { Findings well } \\
\text { described }\end{array}$ \\
\hline Task specific $(n=8)$ & All & All & $\begin{array}{l}\text { All except: } \\
{[34,35,42]}\end{array}$ & None & $\begin{array}{l}\text { All except: } \\
{[36,42]}\end{array}$ & None & $\begin{array}{l}\text { All except: } \\
\text { [42] }\end{array}$ & $\begin{array}{l}\text { All except: } \\
\text { [42] }\end{array}$ & $\begin{array}{l}\text { All except: } \\
{[36,39]}\end{array}$ & $\begin{array}{l}\text { All except: } \\
\text { [34] }\end{array}$ \\
\hline AFO \& FES $(n=7)$ & All & $\begin{array}{l}\text { All except: } \\
{[46]}\end{array}$ & All & $\begin{array}{l}\text { Only by: } \\
{[28,44,45]}\end{array}$ & All & None & All & All & All & All \\
\hline Auditory cueing ( $n=2)$ & All & All & All except: [17] & Only by: [10] & All & None & All & All & All & All \\
\hline Exercise $(n=4)$ & All & All & All & None & All & Only by: [48] & All & All & All & All \\
\hline Imagery $(n=2)$ & All & All & All & None & All & None & All & All & All & All \\
\hline
\end{tabular}

'All', indicates all studies in that treatment category met the item of the Downs and Black [24] checklist.

Table 2.2

Summary of methodological quality of randomised studies.

\begin{tabular}{|c|c|c|c|c|}
\hline Study & Allocation concealment & Blinding of outcome assessor & Intention to treat analysis & Baseline similarity \\
\hline Hornby, 2008 & Yes & No & no & Yes \\
\hline Westlake, 2009 & Unclear & Unclear & $\mathrm{n} / \mathrm{a}$ & Yes \\
\hline Yang, 2007 & Yes & Unclear & $\mathrm{n} / \mathrm{a}$ & Yes \\
\hline Yang, 2005 & Unclear & No & $\mathrm{n} / \mathrm{a}$ & Yes \\
\hline Laufer, 2001 & No & Yes & $\mathrm{n} / \mathrm{a}$ & Yes \\
\hline Schauer, 2003 & Unclear & No & $\mathrm{n} / \mathrm{a}$ & Yes \\
\hline Thaut, 1997 & Unclear & Unclear & $\mathrm{n} / \mathrm{a}$ & Unclear \\
\hline Thaut, 2007 & Yes & Yes & Unclear & Unclear \\
\hline Yavuzer, 2006 & Yes & Yes & No & Yes \\
\hline
\end{tabular}

Not applicable (N/A) was applied to intention-to-treat analysis for any RCT which did not lose any participants to follow up. 
included in meta-analyses but the interventions are described in the results.

Given the range of study methodologies included, results from different study designs were expected to differ systematically, resulting in increased heterogeneity. Consequently, outcome measures were combined and analysed using a random-effects model of the generic inverse variance method, which gives more weight to studies with less variance in the pooled analysis [26] using Review Manager 5 software (RevMan. Copenhagen: the Nordic Cochrane Centre, The Cochrane Collaboration, 2008). Additionally, to obtain an estimate of the effect of the intervention compared to no treatment and to minimize the influence of heterogeneity between studies on this comparison, effect sizes were only calculated for comparisons made before and after the intervention (pre-, post-test) or with and without the experimental conditions/treatment. Results are presented as effect sizes with 95\% confidence interval $(\mathrm{CI})$ and respective $p$-values.

\section{Results}

The search strategy identified 1132 titles. After elimination of duplicates and obviously irrelevant titles $(n=586)$ and screening for fit with the inclusion criteria $(n=145)$ and assessment of methodological quality, 33 studies involving 556 participants were selected. See Fig. 1. Given the broad inclusion criteria for intervention, most of the excluded studies $(n=145)$ were discounted on the basis that outcome measures yielded no extractable data regarding coordination (e.g. step lengths and widths were reported as the average across paretic and non-paretic limbs or gait speed as the only outcome measure) or the study design did not provide a control or baseline measure for comparisons (e.g. participants with stroke were compared to healthy control groups). None of the papers included in this systematic review were books or other reports not subject to peer review.

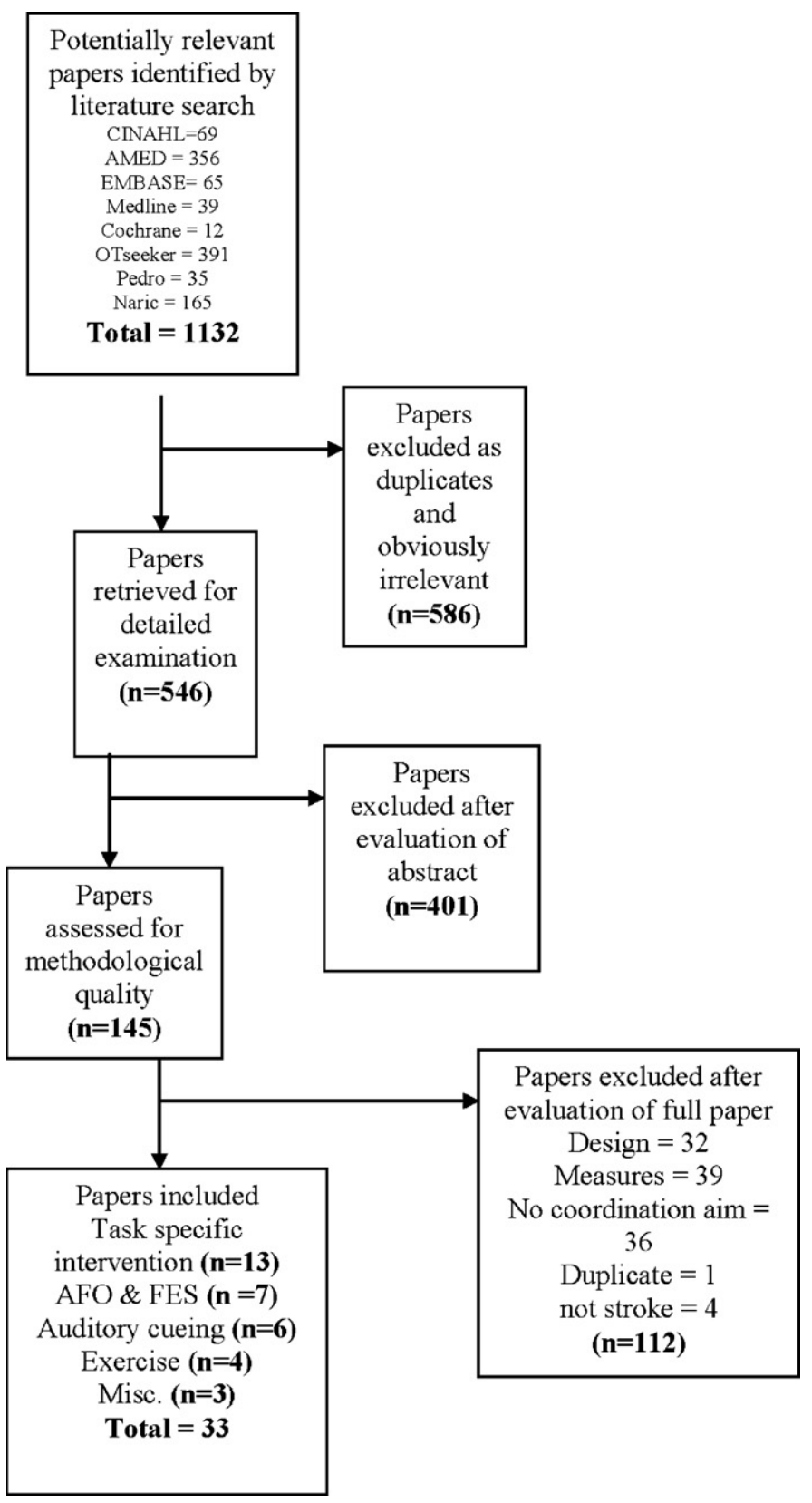

Fig. 1. Illustration of studies identified and their management. 


\subsection{Participants}

Studies recruited on average 17 participants (range 1-58) with all non-randomised studies employing convenience samples. Participants were typically greater than 6 months post-stroke, with only five studies [27-32] involving participants in the acute stages ( $<3$ months) of recovery. Most participants were relatively able, with self-selected walking speeds between $0.4 \mathrm{~m} / \mathrm{s}$ and $0.8 \mathrm{~m} /$ $\mathrm{s}$, indicating they were "limited community walkers" [33]. The participant demographics in the selected trials are presented below (see Table 1 ).

\subsection{Interventions}

The interventions provided were grouped into four types: taskspecific practice of walking $(n=13)$ [10,34-43]; ankle-foot orthoses (AFOs) or functional electrical stimulation (FES) $(n=7)$ $[6,16,23,28,44-46]$; auditory cueing $(n=6)[10,17,29-31,47]$ and exercise $(n=4)$ [32,48-50]. The three remaining studies examined imagery [51,52] and balance training [53]. The intensity with which the interventions were given was broad. Nine studies $[6,10,23,28,34,35,37,39,45]$ only applied the intervention for a few repetitions of walking in a single session but most commonly interventions were delivered over multiple sessions e.g. 36 sessions of locomotor training [36]. Further Details of the interventions given are shown in Tables 3.1-3.5.

\subsection{Design of included studies}

Of the 33 trials, only nine studies ( $n=13-52)$ were randomised controlled trials (RCT) [27,29-31,38,40,43,53,54]. Intention-totreat analysis did not feature in any of these studies. However, attrition was an issue for only two [30,40]; both with an approximate $30 \%$ lost to follow up. Similarly, few studies used blinded outcome assessors. However, this design fault was countered by the use of relatively unbiased measurement procedures (e.g. three dimensional motion analysis and gait analysis). Therefore, generally these studies were of sound methodological design.

All of the remaining studies employed same-subject designs in which participants acted as their own control, hence equality of baseline characteristics was controlled for. Only four included any randomisation, which was in the order in the experimental or control conditions was 'applied', rather than which treatment was received, to minimize detection bias. While none of these studies used blinded assessors, all outcome measurements used standardized protocols and unbiased measurement systems (e.g. three-dimensional motion analysis systems).

Each of the studies utilised different control conditions (e.g. overground walking (OG), treadmill training (TT), therapist assisted walking) and, different control comparisons such as comparisons before and after the intervention (pre-, post-test) or comparing the intervention and control conditions rather than

Table 3.1

Characteristics of design and intervention content for studies examining task specific interventions.

\begin{tabular}{|c|c|c|c|c|}
\hline & Study & Intervention group & Intervention or test condition content & Duration/intensity/frequency \\
\hline 1 & Chen, 2005 & $\begin{array}{l}\text { Control } \\
\text { Experimental }\end{array}$ & $\begin{array}{l}\text { Treadmill walking } 35 \% \text { BWS } \\
\text { Ten conditions involving varied degrees of BWS, } \\
\text { speed and stiffness of hand rail support }\end{array}$ & 1 session of $20 \mathrm{~s}$ walking in each of 10 conditions \\
\hline 2 & Ford, 2007 & $\begin{array}{l}\text { Control } \\
\text { Experimental }\end{array}$ & $\begin{array}{l}\text { Step to the beat on treadmill } \\
\text { Move arms and legs to the beat on treadmill }\end{array}$ & 1 session of 30 s walking in each condition \\
\hline 3 & Harris-Love, 2001 & $\begin{array}{l}\text { Control } \\
\text { Experimental }\end{array}$ & $\begin{array}{l}\text { OG walking } \\
\text { TT }\end{array}$ & 5 trials of each condition \\
\hline 4 & Hornby, 2008 & $\begin{array}{l}\text { Control } \\
\text { Experimental }\end{array}$ & $\begin{array}{l}\text { Therapist assisted TT } \\
\text { Robot assisted TT }\end{array}$ & $\begin{array}{l}12 \text { sessions of } 30 \mathrm{~min} \text {, } \\
12 \text { sessions of } 30 \mathrm{~min} \text {, }\end{array}$ \\
\hline 5 & Lindquist, 2007 & $\begin{array}{l}\text { Control } \\
\text { Experimental }\end{array}$ & $\begin{array}{l}\text { BWS TT } \\
\text { BWS TT + FES }\end{array}$ & 27 sessions of $45 \mathrm{~min}, 3$ days/week for 9 weeks \\
\hline 6 & Plummer, 2007 & $\begin{array}{l}\text { Control } \\
\text { Experimental }\end{array}$ & $\begin{array}{l}\text { Pre-test } \\
\text { BWS TT + OG }\end{array}$ & $\begin{array}{l}\text { Walking over an instrumented walkway on the ground } \\
\text { BWS TTfor } 20-30 \text { min then } 10-15 \text { min of OG walking } \\
\text { and home exercise instruction. } 3 \text { days/week for } 16 \text { weeks. }\end{array}$ \\
\hline 7 & Reisman, 2007 & $\begin{array}{l}\text { Control } \\
\text { Experimental }\end{array}$ & $\begin{array}{l}\text { Pre-test } \\
\text { Split belt TT }\end{array}$ & $\begin{array}{l}2 \text { min treadmill walking at self-selected speed } \\
\text { Split belt } 2 \text { min }\end{array}$ \\
\hline 8 & Waajford, 1990 & $\begin{array}{l}\text { Control } \\
\text { Experimental }\end{array}$ & $\begin{array}{l}\text { Pre-test } \\
\text { TT }\end{array}$ & $\begin{array}{l}\text { Walking } 3 \times \text { over-ground } \\
10 \mathrm{~min} 3 \times / \mathrm{wk}, 3 \text { weeks }\end{array}$ \\
\hline 9 & Westlake, 2009 & $\begin{array}{l}\text { Control } \\
\text { Experimental }\end{array}$ & $\begin{array}{l}\text { Therapist assisted TT } \\
\text { Robot assisted TT }\end{array}$ & $\begin{array}{l}12 \text { sessions ( } 3 \times / \text { wk over } 4 \text { weeks) involving } 30 \mathrm{~min} \\
\text { of stepping per session } \\
12 \text { sessions }(3 \times / \text { wk over } 4 \text { weeks) involving } 30 \mathrm{~min} \text { of } \\
\text { stepping per session }\end{array}$ \\
\hline 10 & Yang, 2007 & Control & $\begin{array}{l}\text { No intervention } \\
\text { Dual task OG }\end{array}$ & $\begin{array}{l}\text { Pre-test consisted of walking } 3 \times \text { over an instrumented } \\
\text { pathway on the ground } \\
30 \text { min ball exercise program with dual task } 3 \times / \text { week } \\
\text { for } 4 \text { weeks }\end{array}$ \\
\hline 11 & Yang, 2005 & Control & $\begin{array}{l}\text { Conventional training (strength, } \\
\text { endurance exercises and gait practice) } \\
\text { Backward walking practice }\end{array}$ & $\begin{array}{l}40 \mathrm{~min} 3 \times / \text { week for } 3 \text { weeks } \\
40 \mathrm{~min} 3 \times / \text { week for } 3 \text { weeks }\end{array}$ \\
\hline 12 & McCain, 2008 & $\begin{array}{l}\text { Control } \\
\text { Experimental }\end{array}$ & $\begin{array}{l}\text { Comparison group (in patient rehab services) } \\
\text { TT + BWS }\end{array}$ & $\begin{array}{l}3 \mathrm{~h} \text { of daily rehabilitation service for duration of inpatient stay } \\
30 \text { min gait training }+30 \text { min mobility practice }+2 \mathrm{~h} \text { regular } \\
\text { therapy content, daily for duration of inpatient stay }\end{array}$ \\
\hline 13 & Laufer, 2001 & $\begin{array}{l}\text { Control } \\
\text { Experimental }\end{array}$ & $\begin{array}{l}\text { OG } \\
\text { TT }\end{array}$ & $\begin{array}{l}5 \times / \text { week for } 3 \text { weeks, } 8-20 \mathrm{~min} \text { of walking } \\
5 \times / \text { week for } 3 \text { weeks, } 8-20 \mathrm{~min} \text { of walking }\end{array}$ \\
\hline
\end{tabular}

$\mathrm{TT}=$ treadmill training, BWS = body weight support, $\mathrm{OG}=$ overground walking, $\mathrm{FES}=$ functional electrical stimulation. 
Table 3.2

Characteristics of design and intervention content for studies examining ankle-foot orthotic interventions.

\begin{tabular}{|c|c|c|c|c|}
\hline & Study & Intervention group & Intervention or test condition content & Duration/intensity/frequency \\
\hline 1 & Hausdorff, 2008 & $\begin{array}{l}\text { Control } \\
\text { Experimental }\end{array}$ & $\begin{array}{l}\text { Baseline measures Walking without FES } \\
\text { FES neuroprosthesis }\end{array}$ & $\begin{array}{l}\text { Walking a } 50 \mathrm{~m} \text { pathway repetitively for } 6 \mathrm{~min} \\
\text { Daily use of neuroprosthesis for entire day for } 8 \text { weeks }\end{array}$ \\
\hline \multirow[t]{2}{*}{2} & Krishnam-oorthy, 2008 & Control & $\begin{array}{l}\text { Baseline measures walking without } \\
\text { FES or AFO }\end{array}$ & Walking over-ground $5 \times$ \\
\hline & & Experimental & Gravity balanced AFO + FES + feedback & $\begin{array}{l}\text { Gradual increase of intensity in intervention parameters } \\
\text { over } 15 \text { days of training }\end{array}$ \\
\hline 3 & Lehmann, 1987 & $\begin{array}{l}\text { Control } \\
\text { Experimental }\end{array}$ & $\begin{array}{l}\text { Walking without AFO } \\
\text { Walking with an AFO }\end{array}$ & $\begin{array}{l}\text { Six trials of walking without AFO } \\
\text { Six trials of walking with AFO }\end{array}$ \\
\hline 4 & Jones, 1999 & $\begin{array}{l}\text { Control } \\
\text { Experimental }\end{array}$ & $\begin{array}{l}\text { Walking without AFO } \\
\text { Serial casting }\end{array}$ & $\begin{array}{l}\text { Walking over-ground } 3 \times \text { for } 8 \mathrm{~m} \\
4 \text { weeks of cast wearing }\end{array}$ \\
\hline 5 & Wang, 2007 & $\begin{array}{l}\text { Control } \\
\text { Experimental }\end{array}$ & $\begin{array}{l}\text { Walking without AFO } \\
\text { Walking with an AFO }\end{array}$ & $\begin{array}{l}\text { Walking } 3 \times \text { over } 10 \mathrm{~m} \text { instrumented pathway on the ground } \\
\text { Standard posterior leaf } A F O \text {, worn for three walks on } \\
\text { a } 10 \mathrm{~m} \text { pathway }\end{array}$ \\
\hline 6 & Tyson, 2001 & $\begin{array}{l}\text { Control } \\
\text { Experimental }\end{array}$ & $\begin{array}{l}\text { Walking without AFO } \\
\text { Walking with an AFO }\end{array}$ & $\begin{array}{l}6 \times 5 \mathrm{~m} \text { walks without AFO } \\
6 \times 5 \mathrm{~m} \text { walks with AFO }\end{array}$ \\
\hline 7 & Tyson, 1998 & $\begin{array}{l}\text { Control } \\
\text { Experimental }\end{array}$ & $\begin{array}{l}\text { Walking without AFO } \\
\text { Walking with an AFO }\end{array}$ & $\begin{array}{l}1 \times \text { walk over } 5 \mathrm{~m} \text { without AFO } \\
1 \times \text { walk over } 5 \mathrm{~m} \text { with hinged AFO with plantar stop }\end{array}$ \\
\hline
\end{tabular}

$\mathrm{AFO}=$ ankle foot orthotic, $\mathrm{FES}=$ functional electrical stimulation.

Table 3.3

Characteristics of design and intervention content for studies examining auditory cueing interventions.

\begin{tabular}{|c|c|c|c|c|}
\hline & Study & Intervention group & Intervention content & Duration/intensity/frequency \\
\hline \multirow[t]{2}{*}{1} & Schauer, 2003 & Control & Bobath & Bobath therapy 45 min per day 5 days/week \\
\hline & & Experimental & $\begin{array}{l}\text { Bobath plus musical motor feedback } \\
\text { walking practice }\end{array}$ & $\begin{array}{l}5 \text { days/week, } 20 \text { min musical walking practice }+45 \text { min } \\
\text { Bobath treatment }\end{array}$ \\
\hline \multirow[t]{2}{*}{2} & Thaut, 1997 & Control & Bobath & 6 weeks $2 \times /$ day, 30 min $5 \times /$ week Bobath therapy \\
\hline & & Experimental & Auditory cueing & $\begin{array}{l}6 \text { weeks } 2 \times / \text { day, } 30 \mathrm{~min} 5 \times / \text { week, rhythmic stimulus used to } \\
\text { drive music to regulate walking practice }\end{array}$ \\
\hline \multirow[t]{2}{*}{3} & Thaut, 2007 & Control & Bobath & 3 weeks, 30 min daily $5 \times /$ week Bobath therapy \\
\hline & & Experimental & Auditory cueing & $\begin{array}{l}3 \text { weeks, } 30 \text { min daily } 5 \times / \text { week, rhythmic stimulus used to } \\
\text { drive music to regulate walking practice }\end{array}$ \\
\hline \multirow[t]{2}{*}{4} & Roerdink, 2007 & Control & No auditory pacing & $\begin{array}{l}90 \text { s treadmill walking at each of the three belt speeds } \\
\text { (i.e. slow, comfortable, and fast) }\end{array}$ \\
\hline & & Experimental & Auditory cueing on TT & Treadmill walking with acoustic pacing $3 \mathrm{~min}$. \\
\hline \multirow[t]{2}{*}{5} & Prassas, 1997 & Control & No auditory cueing & Walking over-ground at self-selected pace for $3 \mathrm{~min}$ \\
\hline & & Experimental & Stepping to accentuated beats of music & 3 testing sessions over a 5 week period \\
\hline
\end{tabular}

$\mathrm{TT}=$ treadmill training.

Table 3.4

Characteristics of design and intervention content for studies examining exercise interventions.

\begin{tabular}{|c|c|c|c|c|}
\hline & Study & Intervention group & Intervention content & Duration/intensity/frequency \\
\hline 1 & Silver, 2000 & $\begin{array}{l}\text { Control } \\
\text { Experimental }\end{array}$ & $\begin{array}{l}\text { Pre-test } \\
\text { Treadmill exercise }\end{array}$ & $\begin{array}{l}\text { Six trials of walking } 3.1 \mathrm{~m} \text { over-ground. } \\
3 \times \text { week, } 3 \text { months. Intensity increased up to } 40 \mathrm{~min} \text { at } 60-70 \% \max \mathrm{HRR}\end{array}$ \\
\hline 2 & Sibley, 2008 & $\begin{array}{l}\text { Control } \\
\text { Experimental }\end{array}$ & $\begin{array}{l}\text { Pre-test } \\
\text { Semi-recumbant cycle ergometer }\end{array}$ & $\begin{array}{l}\text { Three trials of walking } 6 \mathrm{~m} \text { over-ground on instrumented walkway } \\
\text { One session, pedal } 50 \mathrm{rpm} \text { with work rate increased at } 5 \mathrm{~W} / \mathrm{min}\end{array}$ \\
\hline 3 & Coombs, 2007 & $\begin{array}{l}\text { Control } \\
\text { Experimental }\end{array}$ & $\begin{array}{l}\text { Pre-test } \\
\text { Strength training for paretic } \\
\text { limb + BWS TT }\end{array}$ & $\begin{array}{l}\text { Two repetitions of walking } 20 \mathrm{~m} \text { over-ground. } \\
3 \times \text { week, } 6 \text { weeks. } 20 \text { min Lower limb strength training }(3 \times 5 \text { reps } \\
\text { increased to } 5 \times 5 \text { reps then increased weight): isokinetic exercise, } \\
\text { step ups, seated knee extension and prone flexion, seated ankle } \\
\text { plantar/dorsi-flexion }+10 \text { min BWS TT }\end{array}$ \\
\hline 4 & Patterson, 2008 & $\begin{array}{l}\text { Control } \\
\text { Experimental }\end{array}$ & $\begin{array}{l}\text { Pre-test } \\
\text { Treadmill exercise }\end{array}$ & $\begin{array}{l}\text { Three trials of walking } 7 \mathrm{~m} \text { over-ground } \\
3 \times \text { week, } 6 \text { months up to max intensity of } 40 \mathrm{~min} \text { at } 60-70 \% \text { max HRR }\end{array}$ \\
\hline
\end{tabular}

HRR $=$ heart rate reserve.

intervention and control groups. Key design features of the selected studies are detailed in Tables 2.1-2.2, with separate tables summarising design features of randomised and nonrandomised studies.

\subsection{Outcome measures}

All the studies except two [38,48], expressed gait coordination through measures of temporal and spatial symmetry, although the 
Table 3.5

Characteristics of design and intervention content for studies examining miscellaneous interventions.

\begin{tabular}{|c|c|c|c|c|}
\hline & Study & Intervention group & Intervention or test condition content & Duration/intensity/frequency \\
\hline \multirow[t]{2}{*}{1} & Dunsky, 2008 & Control & Pre-test & 4 trials of walking $6 \mathrm{~m}$ over-ground \\
\hline & & Experimental & $\begin{array}{l}\text { Imagery of paretic limb push-off, } \\
\text { gait speed and symmetry }\end{array}$ & $15-20$ min $3 \times$ week, 6 weeks. \\
\hline \multirow[t]{2}{*}{2} & Dickstein, 2004 & Control & Pre-test & 6 trials of walking $6 \mathrm{~m}$ over-ground \\
\hline & & Experimental & $\begin{array}{l}\text { Imagery of paretic limb push-off, } \\
\text { gait speed and symmetry }\end{array}$ & $15-20 \min 3 \times$ week, 6 weeks \\
\hline \multirow[t]{2}{*}{3} & Yavuzer, 2006 & Control & Conventional inpatient rehabilitation & $\begin{array}{l}2-5 \text { h/day, } 5 \text { days/week for } 8 \text { weeks } \\
\text { multidisciplinary rehabilitation }\end{array}$ \\
\hline & & Experimental & Balance training & $\begin{array}{l}\text { Conventional rehabilitation }+15 \mathrm{~min} \text {, } \\
5 \text { days/week for } 3 \text { weeks balance training }\end{array}$ \\
\hline
\end{tabular}

methods of calculation varied. These quantified coordination through relative phase between thorax and pelvis [34] and interlimb phase relationships [37].

\subsection{Effect of interventions on gait coordination and speed}

Data from 19 studies were entered in to the meta-analysis to assess the effects the interventions on gait coordination (Fig. 2) and gait speed (Fig. 3). A sub-group analysis was also carried out to assess the effect of each type of intervention on the outcomes.

When combined, the interventions had a moderate, positive effect on gait co-ordination (effect size $[95 \% \mathrm{CI}]=0.38[0.05,0.72]$ ). However only auditory cueing showed a significantly positive (in that the participants' gait became more symmetrical) effect when the different types of intervention were considered individually (effect size $[95 \% \mathrm{CI}]$ 0.82, $[-0.00,1.64]$ ). Exercise showed a

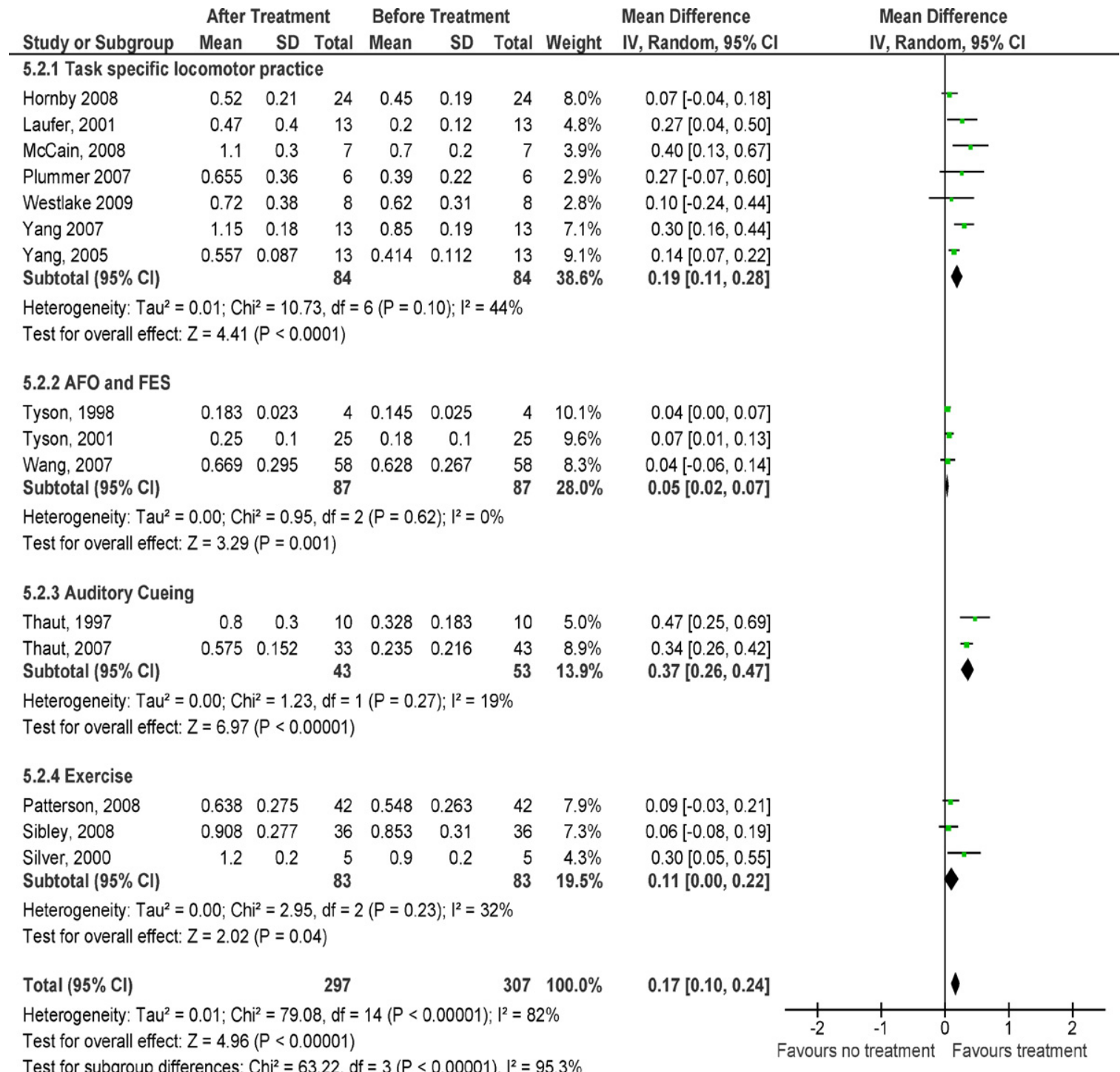

Fig. 2. Forest of the effect of all treatment subcategories on self-selected gait symmetry. 
K.L. Hollands et al./Gait E' Posture $x x x(2011) x x x-x x x$

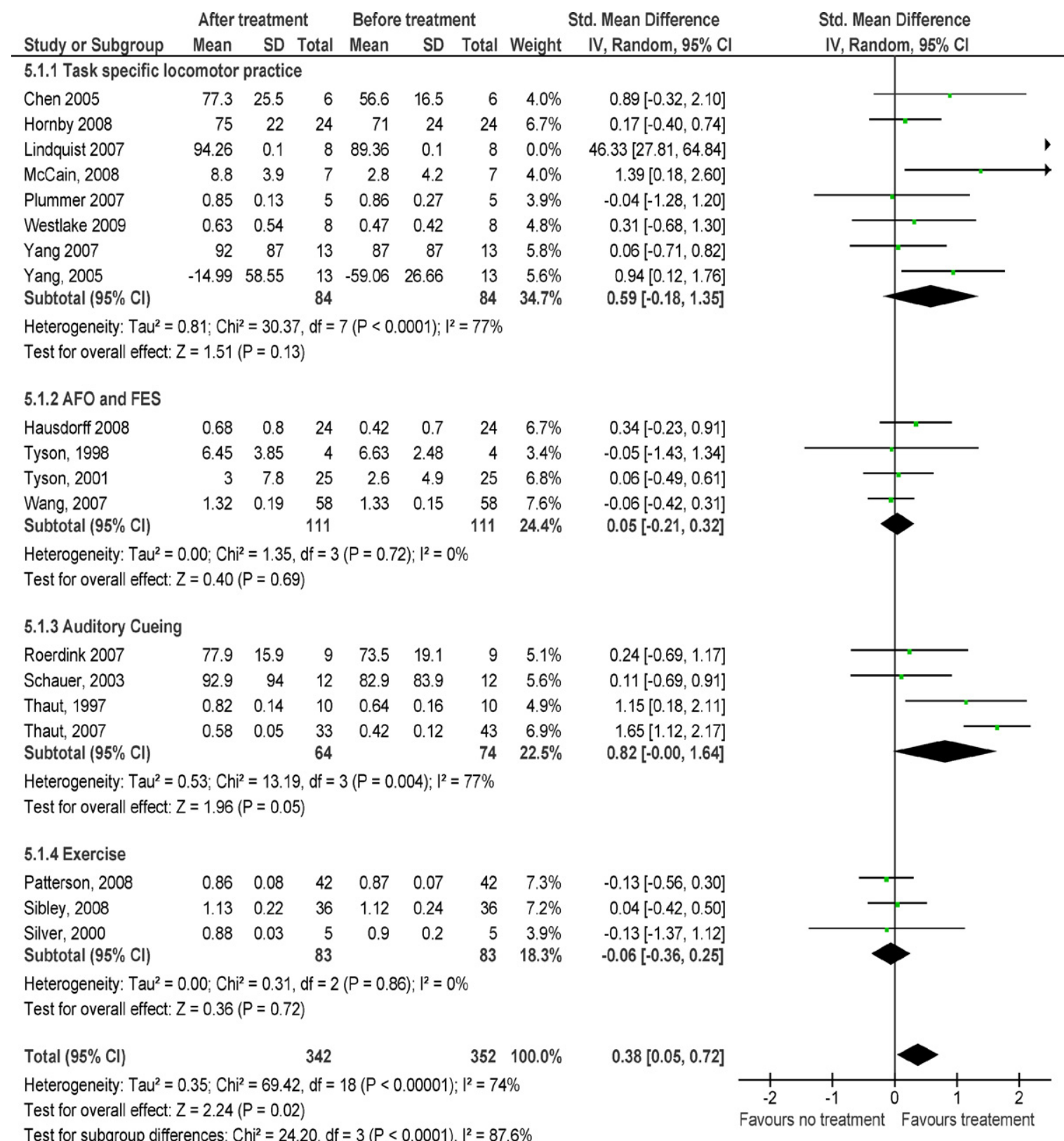

Fig. 3. Forest plots of the effect of treatment subcategories on gait speed.

non-significant negative effect, in that the patients gait became less symmetrical during or after the intervention $(-0.06,[-0.36,0.25])$.

Overall, the interventions showed significant improvements on gait speed (effect size [95\% CI] $0.17 \mathrm{~m} / \mathrm{s}[0.10,0.24]$ ). Each type of intervention also showed a positive effect. Auditory cueing showed the greatest effect $(0.37 \mathrm{~m} / \mathrm{s}[0.26,0.47])$, task specific practice and exercise had small but positive effects $(0.11 \mathrm{~m} / \mathrm{s}[0.00,0.22]$ and $0.19 \mathrm{~m} / \mathrm{s}$ [0.11, 0.28] respectively), while orthoses and FES produced the least change $(0.05 \mathrm{~m} / \mathrm{s}[0.02,0.07])$.

\section{Discussion}

This review aimed to identify interventions used to treat gait coordination impairments, their theoretical basis and any evidence for their effects in order to identify those warranting further investigation. We found few high quality RCTs with a low risk of bias and so, pragmatically, included non-randomised study designs, but limited the influence of heterogeneity by restricting meta-analyses to comparisons of experimental interventions with no intervention. The inclusion of all study designs enabled us to establish the "state-of-the-art" in the treatment of gait coordination, but in doing so results should be treated as indications for future research and development rather than definitive evidence of effectiveness.

Four main interventions that directly targeted gait coordination impairments were identified: task specific locomotor training (including over ground and treadmill training with or without body weight support), ankle foot orthotics (AFO) and functional electrical stimulation (FES), auditory cueing and exercise. Exercise and AFO/FES interventions aim to improve walking coordination by compensating for underlying deficits. AFOs prevent foot-drop and promote heel contact [45], while exercise improves neuromuscular and cardiovascular function [49] which often wanes with inactivity following a stroke. The remaining interventions are hypothesized [35] to improve gait coordination by stimulating cortical reorganisation through the repeated exposure to a more 
normalized gait pattern. Treadmill training provides repetitive practice of a gait pattern in which the paretic limb is driven in a more biophysically desirable manner [35] (i.e. normalizing both sensory and motor events), while auditory cueing provides a reference frame to stabilize time relationships of gait events [30]. However, the few attempts to quantify the neuroplastic changes associated with physiotherapy interventions for walking to date, suggest increases in sensorimotor cortex and subcortical activity following treadmill training but it is unclear whether this represented plasticity or compensatory activation [55,56]. Therefore, at present, the rational for different interventions is still weak and requires a better understanding of the nature of both neuroplasticity and coordination deficits in functional tasks after stroke.

This review sought to advance our knowledge of the role gait coordination impairments may play in functional walking deficits, by pooling the evidence from all relevant study designs for the effects of interventions on gait coordination and walking ability.

Overall, the interventions improved both coordination and gait function (speed). When considered individually, each type of intervention also improved gait function but for co-ordination, the only intervention to show a significant benefit was auditory cueing. This result may have been influenced by the inclusion of non-randomised experimental study designs, as results from these studies are more open to bias towards positive effects. This result should therefore be regarded as indicative rather than a definitive establishment of effectiveness for auditory cueing. The lack of significant findings for the other three interventions may have been affected by the fact that the selected trials were small and did not use sample size calculations, and so comparisons may be been under-powered even when the results were pooled.

The interventions that showed the most promise (auditory cueing and task-specific practice) included all the RCTs thereby giving the most validity to their effect. Most reduced risk of bias introduced from a lack of blinding of outcome assessor and intention-to-treat analyses, by the use of unbiased measurement procedures and limited loss of data at follow up respectively. However, none examined the transfer of stepping skills obtained during an intervention to walking in everyday life, the ability to adapt to the environment and one's behavioural goals [36]. Consequently, it is not known whether the improvements in coordination reported in the trials would transfer changes in activity in everyday life, or were merely a performance effect. Future trials need to include these outcomes to elucidate the potential functional benefits (or not) of specifically targeting co-ordination and symmetry as rehabilitation goals.

Orthotics and exercise did not show a significant effect on coordination and given that they involved the least robust designs that are biased in favour of a positive effect, then one could conclude that these interventions do not affect co-ordination. However, none of the trials included a sample size calculation and involved small numbers, so even the pooled analysis could be under-powered. Furthermore all the studies involved highly selected convenience samples; most participants were in the chronic stages of stroke ( $>6$ months) and were 'community walkers' [33]. Ultimately, such small and selected samples limit external validity and prevent translation of this evidence into recommendations for clinical practice. Future research needs to involve samples that are adequately powered to produce a functionally relevant effect and use pragmatic recruitment strategies so that people with more severe activity limitations and in the acute stages of stroke recovery, who are more typical of the individuals receiving stroke rehabilitation are included.

The finding that improvements in gait coordination were found alongside increased walking speed lends support to the hypothesis that interventions, such as auditory cueing, targeting lower limb coordination may be a mechanism by which improvements in walking activity can be achieved. They also lend support to the notion that repeated exposure to normalized movement patterns can potentiate neuro-plasticity and bring about positive changes in motor control [21,35]; which is the construct underlying many physiotherapy interventions and approaches. The two interventions that showed most promise (task specific locomotor practice and auditory cueing) both involve repetition of a more normative gait pattern, while the least beneficial (exercise) does not explicitly practice a normative gait pattern. As such, it lends further support to the development of interventions that enable patients to undertake intensive practice of functional tasks in a manner that drives an optomised movement pattern.

The validity of the rehabilitation goal of normalizing gait patterns, particularly coordination (as measured by symmetry), is controversial given that enduring neuro-muscular and gait asymmetries persist after stroke [1] and, some studies have shown, these impairments have little relationship to function or recovery $[1,21]$. The lack of relationship between gait coordination and functional walking ability suggests that improvements in function occur in spite, or possibly because, of compensatory strategies. However, other studies have found direct links between motor impairment and walking function. For example, independence in walking (function) has been correlated with lower-limb strength (impairment) [29] and reduced motor coordination has been correlated with poorer motor recovery [12]. None of the included trials targeting walking co-ordination in this review sought to evaluate the mechanisms underlying the changes found. So it is not known whether changes in walking function (speed) were driven by restoration of the movement pattern (symmetry), or of neural function, or by compensatory means. Establishing the mechanism by which functional gains are achieved is important to ensure that interventions are effectively maximising functional outcomes [57] and can be appropriately targeted and adapted to individual needs.

\section{Limitations}

The main limitation of this study is that we have included trials that used non-randomised designs that could be biased in favour of a beneficial effect; therefore, our results may be similarly biased. We acknowledge this, and reiterate that the results of this review should be treated with caution and should not be considered definitive evidence of effectiveness. Our aim in undertaking this review was to establish the 'state of the art' for co-ordination of walking, to establish what evidence there was to inform future research directions, rather than to establish the effectiveness of interventions. Hence, we feel our choice of design was reasonable.

Most of the studies included in this review measure coordination through indices of gait symmetry. Therefore, this review is limited by the extent to which symmetry reflects gait coordination. As discussed above, the validity of gait symmetry as a goal for rehabilitation after stroke is controversial [1] and others have argued that symmetry is an incomplete descriptor of coordination as it can also be measured for ipsilateral limbs, which need not necessarily be symmetrical (e.g. the paretic arm and leg of stroke patients). However, asymmetries in spatiotemporal, kinematic, and kinetic parameters of walking are related to disturbances in motor coordination [58] and those with an asymmetrical gait pattern have a higher metabolic cost [59], increased risk of joint degeneration [60] and bone density loss in the paretic limb [60,61]. Furthermore, temporal asymmetry is correlated, in varying degrees, with motor recovery, walking speed, strength, spasticity and falls $[21,28,44,62]$; suggesting that gait symmetry validly reflects an important aspect of impairment in gait coordination. 


\section{Conclusions}

The results of this review indicate that interventions involving auditory cueing and task-specific practice of walking may positively influence gait coordination after stroke. The fact that overall improvements in gait coordination coincided with increased walking speed lends support to the hypothesis that interventions targeting lower limb coordination may be a mechanism to improve walking for some people with stroke. However, establishing the mechanism for such improved control requires a better understanding of the nature of both neuroplasticity and of coordination deficits in functional tasks after stroke. Future research requires not only high-quality studies of effectiveness but the measurement of both temporal and spatial aspects of coordination, cortical activation and the impact on activity in everyday life, in order to establish the mechanisms by which functional gains are achieved.

\section{Acknowledgement}

This work was funded by a Stroke Association project grant awarded to Drs Paulette van Vliet and Mark Hollands.

\section{Conflict of interest}

None.

\section{References}

[1] Krasovsky T, Levin MF. Review: toward a better understanding of coordination in healthy and poststroke gait. Neurorehabilitation and Neural Repair 2010;24:213-24

[2] Lamontagne A, De Serres SJ, Fung J, Paquet N. Stroke affects the coordination and stabilization of head, thorax and pelvis during voluntary horizontal head motions performed in walking. Clinical Neurophysiology 2005;116:101-11.

[3] Wagenaar RC, Beek WJ. Hemiplegic gait: a kinematic analysis using walking speed as a basis. Journal of Biomechanics 1992;25:1007-15.

[4] Dally JJ, Sng K, Roenigk K, Fredrickson E, Dohring M. Intra-limb coordination deficit in stroke survivors and response to treatment. Gait and Posture 2007;25:412.

[5] Kim CM, Eng JJ. Symmetry in vertical ground reaction force is accompanied by symmetry in temporal but not distance variables of gait in persons with stroke. Gait and Posture 2003;18:23-8.

[6] Lehmann JF, Condon SM, Price R, DeLateur BJ. Gait abnormalities in hemiplegia: their correction by ankle-foot orthoses. Archives of Physical Medicine and Rehabilitation 1987;68:763-71.

[7] Griffin MP, Olney SJ, McBride ID. Role of symmetry in gait performance of stroke subjects with hemiplegia. Gait and Posture 1995;3:132-42.

[8] Barela JA, Whitall J, Black P, Clark JE. An examination of constraints affecting the intralimb coordination of hemiparetic gait. Human Movement Science 2000;19:251-73.

[9] Dickstein R. Rehabilitation of gait speed after stroke: a critical review of intervention approaches. Neurorehabilitation and Neural Repair 2008;22: 649-60.

[10] Roerdink M, Lamoth CJ, Kwakkel G, et al. Gait coordination after stroke: benefits of acoustically paced treadmill walking. Physical Therapy 2007;87: 1009-22.

[11] Weerdesteyn V, Rijken H, Geurts AC, et al. A five-week exercise program can reduce falls and improve obstacle avoidance in the elderly. Gerontology 2006;52:131-41.

[12] Kautz S, Brown D. Relationships between timing of muscle excitation and impaired motor performance during cyclical lower extremity movement in post-stroke hemiplegia. Brain 1998;121:515-26.

[13] Hyndman D, Ashburn A, Stack E. Fall events among people with stroke living in the community: circumstances of falls and characteristics of fallers. Archives of Physical Medicine and Rehabilitation 2002;83:165-70.

[14] Hill KE, Bernhardt PJ. Balance and mobility outcomes for stroke patients: a comprehensive audit. Australian Journal of Physiotherapy 1997;43:173-80.

[15] Moseley AM, Stark A, Cameron ID, Pollock A. Treadmill training and body weight support for walking after stroke. Cochrane Database of Systematic Reviews 2005. CD002840.

[16] Krishnamoorthy V, Hsu WL, Kesar TM, et al. Gait training after stroke: a pilot study combining a gravity-balanced orthosis, functional electrical stimulation, and visual feedback. Journal of Neurologic Physical Therapy 2008;32:192202.

[17] Prassas S, Thaut M, McIntosh G, Rice R. Effect of auditory rhythmic cuing on gait kinematic parameters of stroke patients. Gait and Posture 1997;6(December (3)):218-23.
[18] WHO. World Health Organisation task force recommendations on stroke prevention, diagnosis and therapy Stroke 1989:20:1407-31.

[19] Olney SJ, Griffin MP, McBride ID. Temporal, kinematic, and kinetic variables related to gait speed in subjects with hemiplegia: a regression approach Physical Therapy 1994;74:872-85.

[20] Lord SEH, Wade PWDT. Visual gait analysis: the development of a clinical assessment and scale. Clinical Rehabilitation 1998;12:107-19.

[21] Patterson KK, Parafianowicz I, Danells CJ, et al. Gait asymmetry in communityambulating stroke survivors. Archives of Physical Medicine and Rehabilitation 2008;89:304-10.

[22] Deeks J, Higgins J, Altman D. Analysing and presenting results: section 8. In: Higgins JPT, Green S, editors. Cochrane handbook for systematic reviews of interventions. 426th ed., Chichester: John Wiley \& Sons Ltd; 2006.

[23] Tyson S, Thornton H, Downes A. The effect of a hinged ankle-foot orthosis on hemiplegic gait: four single case studies. Physiotherapy Theory \& Practice 1998;14:75.

[24] Downs SH, Black N. The feasability of creating a checklist for the assessment of the methodological quality both of randomised and non-randomised studies of health care interventions. Journal of Epidemiology and Community Health 1998;52:377-84

[25] Patterson KK, Gage WH, Brooks D, et al. Evaluation of gait symmetry after stroke: a comparison of current methods and recommendations for standardization. Gait and Posture 2010;31:241-6.

[26] Deeks J, Altman D, Bradburn M, editors. Statistical methods for examining heterogeneity and combining results from several studies in meta-analysis. 2nd ed., London: BMJ; 2001.

[27] Laufer Y, Dickstein R, Chefez Y, Marcovitz E. The effect of treadmill training on the ambulation of stroke survivors in the early stages of rehabilitation: a randomized study. Journal of Rehabilitation Research and Development 2001;38:69-78.

[28] Wang RY, Lin PY, Lee CC, Yang YR. Gait and balance performance improvements attributable to ankle-foot orthosis in subjects with hemiparesis. American Journal of Physical Medicine \& Rehabilitation 2007;86:556-62.

[29] Schauer M, Mauritz KH. Musical motor feedback (MMF) in walking hemiparetic stroke patients: randomized trials of gait improvement. Clinical Rehabilitation 2003; 17:713-22.

[30] Thaut M, Leins A, Rice R, et al. Rhythmic auditory stimulation improves gait more than NDT/Bobath training in near-ambulatory patients early poststroke: a single-blind, randomized trial. Neurorehabilitation and Neural Repair 2007;21:455-9.

[31] Thaut MH, McIntosh GC, Rice RR. Rhythmic facilitation of gait training in hemiparetic stroke rehabilitation. Journal of Neurological Sciences 1997;151: 207-12.

[32] Sibley KM, Tang A, Brooks D, McIlroy WE. Effects of extended effortful activity on spatio-temporal parameters of gait in individuals with stroke. Gait and Posture 2008;27:387.

[33] Perry J, Garrett M, Gronley JK, Mulroy SJ. Classification of walking handicap in the stroke population. Stroke 1995;26:982-9.

[34] Ford MP, Wagenaar RC, Newell KM. The effects of auditory rhythms and instruction on walking patterns in individuals post stroke. Gait and Posture 2007;26:150-5.

[35] Harris-Love ML, Forrester LW, Macko RF, et al. Hemiparetic gait parameters in overground versus treadmill walking. Neurorehabilitation and Neural Repair 2001;15:105-12.

[36] Plummer P, Behrman AL, Duncan PW, et al. Effects of stroke severity and training duration on locomotor recovery after stroke: a pilot study. Neurorehabilitation and Neural Repair 2007;21:137-51.

[37] Reisman DS, Wityk R, Silver K, Bastian AJ. Locomotor adaptation on a split-belt treadmill can improve walking symmetry post-stroke. Brain 2007;130:1861-72.

[38] Westlake KP, Patten C. Pilot study of Lokomat versus manual-assisted treadmill training for locomotor recovery post-stroke. Journal of Neuroengineering and Rehabilitation 2009:6:18.

[39] Chen G, Patten C, Kothari DH, Zajac FE. Gait deviations associated with poststroke hemiparesis: improvement during treadmill walking using weight support, speed, support stiffness, and handrail hold. Gait and Posture 2005; 22:57-62.

[40] Hornby TG, Campbell DD, Kahn JH, et al. Enhanced gait-related improvements after therapist- versus robotic-assisted locomotor training in subjects with chronic stroke: a randomized controlled study. Stroke 2008;39:1786-92.

[41] Lindquist AR, Prado CL, Barros RM, et al. Gait training combining partial bodyweight support, a treadmill, and functional electrical stimulation: effects on poststroke gait. Physical Therapy 2007:87:1144-54.

[42] Waagfjord J, Levangie PK, Certo CM. Effects of treadmill training on gait in a hemiparetic patient. Physical Therapy 1990;70:549-58.

[43] Yang Y-R, Wang R-Y, Chen Y-C, Kao M-J. Dual-task exercise improves walking ability in chronic stroke: a randomized controlled trial. Archives of Physical Medicine and Rehabilitation 2007;88:1236-40.

[44] Hausdorff JM, Ring H. Effects of a new radio frequency-controlled neuroprosthesis on gait symmetry and rhythmicity in patients with chronic hemiparesis. American Journal of Physical Medicine \& Rehabilitation 2008;87:4.

[45] Tyson SF, Thornton HA. The effect of a hinged ankle foot orthosis on hemiplegic gait: objective measures and users' opinions. Clinical Rehabilitation 2001; 15:53.

[46] Jones CA. Effect of lower extremity serial casts on hemiparetic gait patterns in adults Effect of lower extremity serial casts on hemiparetic gait patterns in adults. Physical Therapy Case Reports 1999;2:221. 
[47] Thaut MH, McIntosh GC, Prassas SG, Rice RR. Effect of rhytmic auditory cuing on temporal stride parameters and EMG patterns in hemiparetic gait of stroke patients. Journal of Neurologic Rehabilitation 1993;7:9-16.

[48] Silver KHC, Macko RF, Forrester LW, et al. Effects of aerobic treadmill training on gait velocity, cadence, and gait symmetry in chronic hemiparetic stroke: a preliminary report. Neurorehabilitation and Neural Repair 2000;14:65-71.

[49] Patterson SL, Rodgers MM, Macko RF, Forrester LW. Effect of treadmill exercise training on spatial and temporal gait parameters in subjects with chronic stroke: a preliminary report. Journal of Rehabilitation Research and Development 2008;45:221-8.

[50] Combs S, Miller EW, Forsyth E. Motor and functional outcomes of a patient post-stroke following combined activity and impairment level training. Physiotherapy Theory \& Practice 2007;23:219-29.

[51] Dickstein R, Dunsky A, Marcovitz E. Motor imagery for gait rehabilitation in post-stroke hemiparesis. Physical Therapy 2004;84:1167-77.

[52] Dunsky A, Diskstein R, Marcovitz E, et al. Home-based motor imagery training for gait rehabilitation of people with chronic poststroke hemiparesis. Archives of Physical Medicine and Rehabilitation 2008;89:1580-8.

[53] Yavuzer G, Eser F, Karakus D, et al. The effects of balance training on gait late afte stroke: a randomized controlled trial. Clinical Rehabilitation 2006;20:960-9.

[54] Yang Y, Yen J, Wang R, et al. Gait outcomes after additional backward walking training in patients with stroke: a randomized controlled trial [with consumer summary]. Clinical Rehabilitation 2005;19:264-73.
[55] Enzinger C, Dawes H, Johansen-Berg H, et al. Brain activity changes associated with treadmill training after stroke. Stroke 2009;40:2460-7.

[56] Luft AR, Macko RF, Forrester LW, et al. Treadmill exercise activates subcortical neural networks and improves walking after stroke: a randomized controlled trial. Stroke 2008;39:3341-50.

[57] Kautz SA, Duncan PW, Perera S, et al. Coordination of hemiparetic locomotion after stroke rehabilitation. Neurorehabilitation and Neural Repair 2005;19: 250-8.

[58] Olney SJ, Richards C. Hemiparetic gait following stroke. Part I: Characteristics. Gait and Posture 1996;4:136-48.

[59] Draper ER. A treadmill-based system for measuring symmetry of gait. Medical Engineering \& Physics 2000;22:215-22.

[60] Norvell DCC, Reiber JM, Maynard GE, Pecoraro C, Weiss JAF NS. The prevalence of knee pain and symptomatic knee osteoarthritis among veteran traumatic amputees and nonamputees. Archives of Physical Medicine and Rehabilitation 2005;86:487-93.

[61] Jorgensen LC, Reeve NJ, Jacobsen JBK. Ambulatory level and asymmetrical weight bearing after stroke affects bone loss in the upper and lower part of the femoral neck differently: bone adaptation after decreased mechanical loading. Bone 2000;27:701-7.

[62] Hsu AL, Tang PF, Jan MH. Analysis of impairments influencing gait velocity and asymmetry of hemiplegic patients after mild to moderate stroke. Archives of Physical Medicine and Rehabilitation 2003;84:1185-93. 